
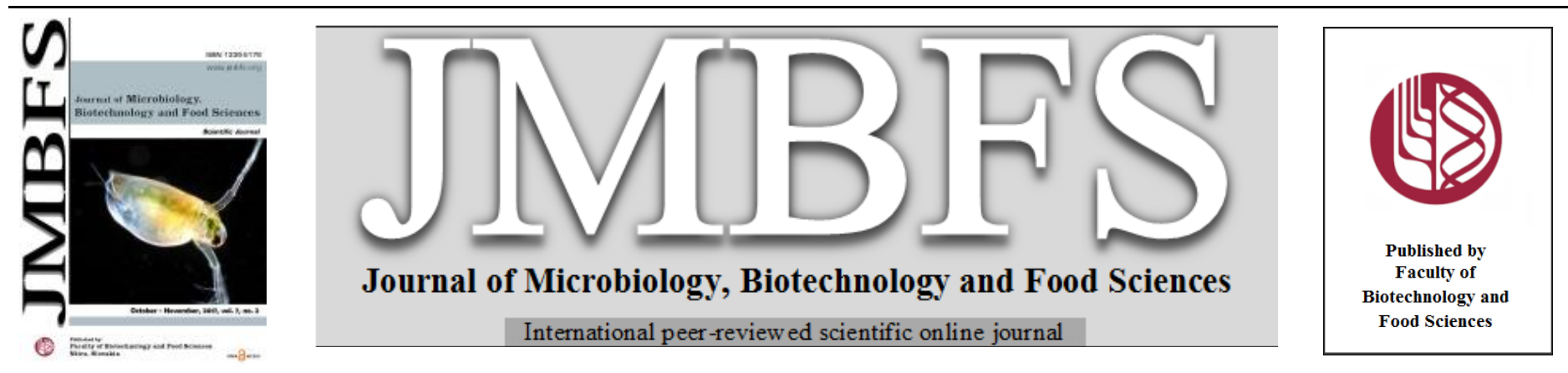

\title{
LOW TAURINE CONCENTRATIONS POSSITIVELY AFFECT RABBIT SPERMATOZOA PROPERTIES IN LATER TIME INTERVALS
}

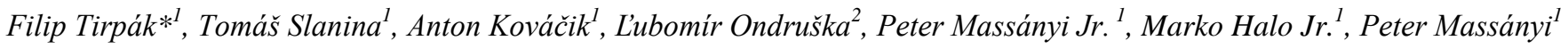 \\ Address(es): Ing. Filip Tirpák \\ ${ }^{1}$ Slovak University of Agriculture in Nitra, Faculty of Biotechnology and Food Sciences, Department of Animal Physiology, Tr. A. Hlinku 2, 949 76, Nitra, Slovak \\ Republic. \\ ${ }^{2}$ Animal Production Research Centre Nitra, NAFC, Hlohovecká 2, 95141 Lužianky, Slovak Republic.
}

*Corresponding author: filip.tirpak@yahoo.com

doi: 10.15414/jmbfs.2017.7.2.128-131

\section{ARTICLE INFO}

Received 31. 5. 2017

Revised 14. 7. 2017

Accepted 13. 8. 2017

Published 1. 10. 2017

Regular article open $\bigodot_{\text {access }}$

\begin{abstract}
The aim of this study was to determinate the effect of various taurine concentrations on rabbit spermatozoa in in vitro conditions with the potential use in routine artificial insemination. Taurine, amino acid distinguished by its strong antioxidant properties, has been widely tested on spermatozoa of all kinds of farm animals except for the rabbits. This study investigated differences in rabbit spermatozoa motility and viability between the control sample and samples enriched with taurine solutions: TAU3 (3.125 mM), TAU6 $(6.250 \mathrm{mM})$ and TAU12 $(12.5 \mathrm{mM})$. Ejaculates of nine adult rabbits were subjected to this study and observed at time intervals 0,90 , 180 and 270 minutes while cultivated at $39^{\circ} \mathrm{C}$. For detection of viability the MTT test was used and motility parameters were carried out using CASA analysis. Experimental samples were compared against the control. Assessment of the mitochondrial toxicity revealed that the addition of taurine ensured the higher viability in supplemented samples however with no statistical significance. Monitored motility parameters (motility, progressive motility and velocity curved line of spermatozoa) showed that taurine treated spermatozoa have lower activity at the beginning of the study but along with increasing time the positive effect of taurine was induced. Significant $(\mathrm{P}<0.05)$ values were observed in velocity curved line in time intervals 0 (TAU3 - negative effect: $110.6 \pm 26.85 \mu \mathrm{m} . \mathrm{s}^{-1}$ ) and 180 (TAU6 - positive effect: $\left.105.8 \pm 28.36 \mu \mathrm{m} \cdot \mathrm{s}^{-1}\right)$. Results indicate that taurine antioxidant properties maintain the spermatozoa viability and activity. In spite of the fact that taurine supplemented spermatozoa had lower activity in inceptive time intervals, taurine may find its use as additive with ROS protective properties during long-term storage.
\end{abstract}

Keywords: taurine, CASA, spermatozoa, rabbit, MTT

\section{INTRODUCTION}

The artificial insemination is a routine technique in rabbit breeding. Insemination must take place within 24-48 hours after semen collection due to decreased viability induced by production of free radicals (Carluccio et al., 2004). Reactive oxygen species (ROS) have a beneficial role in spermatozoa functioning enabling spermatozoa to maturate, capacitate, hyperactivate, undergo the acrosome reaction and to fuse with oocyte. However, long time storage of ejaculated semen results in further production of ROS and its accumulation (Kothari et al., 2010) The excessive free radicals production causes the decrease in semen quality resulting from oxidative damage of biomolecules. Large amount of polyunsaturated fatty acids contained in plasma membrane along with low concentration of scavenging enzymes in cytoplasm make spermatozoa vulnerable to ROS (Lucio et al., 2016; Tvrdá et al., 2016). The survival of the spermatozoa depends not only on the storage temperature but also on the interaction of temperature and the composition of storage medium (Carluccio et al., 2004). 2 aminoethane-sulfonic acid has strong antioxidant properties with not entirely clear biochemical mechanism of action (Huxtable, 1992; Ripps and Shen, 2012). Taurine has been identified as a non-permeating spermatozoa cryoprotectant which minimizes the cellular damage (Chhillar et al., 2012) Intracellular taurine is present in cells at high amounts and its role is determined by the cell type. The use of taurine in reproduction comes out of ability to sustain the spermatozoa motility and to take part in spermatozoa capacitation (Tirpák $\boldsymbol{e t}$ al., 2015). The addition of anti-oxidants, especially those which are contained in epididymal and oviductal fluids (e.g., taurine), to semen extenders protects the spermatozoa against the ROS generated during freezing and thawing process (Bucak and Tekin, 2007; Sariözkan et al., 2009). Our study was aimed on the improvement of spermatozoa properties during long time storage. Previous studies on the influence of taurine on bovine (Chen et al., 1993; Chhillar et al., 2012; Sariözkan et al., 2009), ram (Bucak and Tekin, 2007), boar (Jang et al., 2006), goat (Bucak et al., 2009), dog (Michael et al., 2007) and fish (Martínez-
Páramo et al., 2013) spermatozoa reported enhanced parameters associated with successful fertilization. The aim of this study was to examine the effects of taurine on selected rabbit spermatozoa motility and viability parameters during in vitro incubation at $39^{\circ} \mathrm{C}$

\section{MATERIAL AND METHODS}

\section{Semen collection and processing}

Ejaculates were obtained from sexually mature New Zealand White rabbits $(n=9)$, bred at experimental farm of Animal Production Research Centre in Lužianky. Semen collection was accomplished by the use of pre-warmed artificial vagina following the sexual stimulation by a rabbit doe. Consequently, semen was stored at $5^{\circ} \mathrm{C}$. Fresh ejaculates $(30 \mu$ l) were diluted in ratio $1: 7$ with physiological solution ( $\mathrm{NaCl} 0.9 \%$ Braun, B. Braun Melsungen AG, Germany) for the control group (C). Experimental samples were prepared according to the same dilution rate using three concentrations of taurine (Taurine $\geq 99 \%$, Sigma Aldrich, Bratislava, Slovakia) dissolved in the physiological solution. Taurine solutions TAU3 $(3.125 \mathrm{mM})$, TAU6 $(6.250 \mathrm{mM})$, TAU $12(12.5 \mathrm{mM})$ were prepared in advance in order to proper dissolution of taurine.

\section{Assessment of mitochondrial toxicity}

Viability of the spermatozoa treated with taurine was evaluated by the mitochondrial toxicity test (MTT). This colorimetric assay measures the conversion of 3-(4,5-dimetylthiazol-2-yl)-2,5- diphenyltetrazolium bromide (MTT; Sigma-Aldrich, St. Louis, USA) to purple formazan particles. Conversion mediated by mitochondrial succinate dehydrogenase produced by intact mitochondria of viable cells was determined by an ELISA reader (Multiscan FC, ThermoFisher Scientific, Vantaa, Finland) at $570 \mathrm{~nm}$ against $620 \mathrm{~nm}$ wavelength. 
The data were expressed in percentage - comparing to metabolic activity of sperm cells in the control group (Jambor et al., 2017; Tvrdá et al., 2016).

\section{Motility analyses}

Semen analyses were performed using the Computer assisted semen analysis (CASA) method with SpermVision software (Minitube, Tiefenbach, Germany) and the microscope Olympus BX 51 (Olympus, Japan). Semen samples were placed into Makler counting chamber $(10 \mu \mathrm{m}$, Sefi-Medical Instruments, Germany). Measurements of spermatozoa motility were carried out at four time periods $(0,90,180,270$ minutes). For the duration of the experiment, tested samples were stored in incubator at $39^{\circ} \mathrm{C}$. The following spermatozoa characteristics were assessed: motility (MOT), progressive motility (PRO) velocity curved line (VCL). Every single output of the CASA system is the result of 7 diverse sub-measurements of 7 different fields of Makler Counting Chamber (Tirpák et al., 2016; Slanina et al., 2015)

\section{Statistical analyses}

For the comparison of the CASA and MTT results in certain time intervals with the focus on effect of additives on spermatozoa, ANOVA and Dunnett's comparative test were applied using GraphPad Prism 5 (GraphPad Software Inc., USA). All statistical tests were carried out at levels of significance at $\mathrm{P}<0.05$, $\mathrm{P}<0.01$ and $\mathrm{P}<0.001$ and results were interpreted as means and expressed with SD.

\section{RESULTS AND DISCUSSION}

Present study showed moderately increased spermatozoa viability and motility after extension of fresh rabbit ejaculates with various concentrations of taurine. This trend was manifested mainly in later time intervals while incubated at temperature $\left(39^{\circ} \mathrm{C}\right)$ simulating the female reproductive tract temperature.

Cell viability was assessed using MTT test which monitors the production of succinate dehydrogenase - mitochondrial enzyme involved in Krebs cycle. The cell viability of taurine treated semen did not statistically differ from the control group. Experimental group TAU3 produced $24.19 \%$ more formazan particles than control sample, but was overtaken by absorbance of colorimetric change in group TAU6 - 35.53\% higher viability in comparison to the C group. After 270 minutes of incubation tested taurine concentration in sample TAU 12 engendered the $11.87 \%$ higher cell viability than in the fresh rabbit semen (Figure 1).

Asha and Devadasan (2013) suggest that taurine significantly $(\mathrm{P}<0.001)$ elevates the activity of the Krebs cycle enzymes after peroxidative intoxication. Assessment of mitochondrial activity, based on the production of the succinate dehydrogenase, indicates that supplementation of rabbit semen with taurine results in higher cell viability of our experimental samples. Bucak and Tekin (2007), who observed the effect of taurine on cooled ram semen, evaluated the spermatozoa viability using the eosin-nigrosin staining technique. The $100 \mathrm{mM}$ taurine solution, which was the most effective, added to conventionally used extender showed the same percentage (78.3\%) of intact cells as the control group. These findings correspond with Martínez-Páramo et al., (2013) fluorescent viability evaluation where $1 \mathrm{mM}$ of taurine was applied to an extender of European sea bass semen. However, according to Chhillar et al., (2012) bul semen treated with $50 \mathrm{mM}$ of taurine solution had a significantly $(\mathrm{P}<0.05)$ positive effect on viability as compared in its absence.

Motility percentage found immediately after dilution was non-significantly lower in experimental samples. Motility percentage varied from $82.58 \pm 10.62 \%$ to $83.32 \pm 9.00 \%$ while the $\mathrm{C}$ group showed $85.63 \pm 7.76 \%$ motility. Similar tendency appeared after 90 minutes of cultivation when the semen diluted only with the physiological solution overcame the values of all experimental samples. As shown in Figure 2, 180 minutes of incubation resulted in elevated motility with absence of statistical significance in all samples supplemented with taurine. In the last time interval, semen extended with TAU12 solution reached the highest motility percentage $(45.51 \pm 15.81 \%)$ of all tested samples. Other experimental samples $(42.25 \pm 18.21 \% ; 41.56 \pm 16.24 \%)$ were also higher than the control sample $(39.27 \pm 19.00 \%)$

Subjective assessments of spermatozoa motility conducted by Michael $\boldsymbol{e t} \boldsymbol{a l}$., (2007) on dog and by Chhillar et al., (2012) on cattle semen implicated enhanced motility in taurine enriched samples $(2.4 \mathrm{mM}$ and $50 \mathrm{mM})$ with statistical proof $(\mathrm{P}<0.05)$. Taurine addition to insemination doses prior to cryopreservation shows no difference in overall motility between $100 \mathrm{mM}$ concentration of additive and conventional sample (Bucak and Tekin, 2007).

More objective computer assisted semen analysis was performed by other author (Martínez-Páramo et al., 2013; Tirpák et al., 2015) whose results suggest that the most efficient taurine concentrations for the species used in their experiments (fish $-1 \mathrm{mM}$; bull $-200 \mathrm{mM}$ ) had a significantly higher motility after thawing $(\mathrm{P}<0.05)$. Even though slightly increased motility was detected in present study, in general it seems that spermatozoa benefit more from taurine protective properties (added in higher doses) than from its antioxidative properties (used in lower concentrations) when stored at simulated female intracorporal temperature.
The highest progressive motility $(68.00 \pm 12.83 \%)$, assessed in inceptive time interval, was detected in the group C. Continual proportion between raising taurine concentration and progressive motility increase was determined in all experimental samples of initial measurement. Slighter difference between experimental samples and the control was observed after 90 minutes of cultivation when all values were within the range of $60.69 \pm 17.73 \%$ and $63.60 \pm 18.38 \%$. TAU12 was the most effective taurine solution for the maintenance of the highest possible progressive motility $(35.43 \pm 24.43 \%)$ at 180 minute time interval. Very similar percentages of progressive motility were monitored after 270 minutes of incubation while the values ranged from $21.79 \pm 18.09 \%$ to $23.33 \pm 17.97 \%$.

Tirpák et al., (2015) monitored the effect of five taurine concentrations on post thaw progressive motility of bull spermatozoa. The most effective concentration of taurine $(200 \mathrm{mM})$ significantly $(\mathrm{P}<0.001)$ leveled up the progressive motility in times $0,30,60$ and 90 minutes.

Negative effect of taurine on spermatozoa velocity was noted in inceptive time and represented by samples TAU12 and TAU3 $(\mathrm{P}<0.05)$ in Figure 4. The quickest spermatozoa movement was detected in sample TAU6. After 90 minutes of incubation the bar of control sample was the highest $\left(117.40 \pm 27.63 \mu \mathrm{m} . \mathrm{s}^{-1}\right)$. Experimental samples presented to raising tendency dependent on the concentration of taurine. Positive effect of taurine was proved after 180 minutes of cultivation when the increased spermatozoa velocity was observed in all experimental samples compared to the control. Velocity of spermatozoa extended with TAU6 solution was even statistically significant $(\mathrm{P}<0.05)$. Measurements in the latest time interval showed the higher speed of rabbit spermatozoa in experimental samples rather than in control group. Values for the experimental groups TAU3 and TAU6 were fairly the same $\left(76.61 \pm 29.06 \mu \mathrm{m} . \mathrm{s}^{-1} ; 76.23 \pm 27.13\right.$ $\left.\mu \mathrm{m} . \mathrm{s}^{-1}\right)$ while TAU12 $\left(68.61 \pm 26.33 \mu \mathrm{m} . \mathrm{s}^{-1}\right)$ was moderately higher than C group $\left(68.23 \pm 25.05 \mu \mathrm{m} . \mathrm{s}^{-1}\right)$. Positive effect of taurine on motility has been shown after 180 minutes of incubation. Until then, spermatozoa motility in experimental samples was lower than in the control group.

CASA assessments revealed for Tirpák et al., (2015) that supplementation of bull insemination doses with taurine $(50 \mathrm{mM}, 100 \mathrm{mM}, 200 \mathrm{mM}$ and $400 \mathrm{mM})$ highly $(\mathrm{P}<0.01$ and $\mathrm{P}<0.001)$ increases the $\mathrm{VCL}$ following the thawing process. The same analyzing system was used by Martínez-Páramo et al., (2013) for the analysis of the effect of taurine on cryopreservated sperm of Sea bass although the significant difference between the control sample and sample enriched with $1 \mathrm{mM}$ of taurine was not observed.

Cryopreservation is the biotechnological method successfully applied in domestic animals breeding worldwide; however, rabbit semen processing for cryo storage is still very complicated. The storage of cooled rabbit spermatozoa is the only effective technique for rabbit artificial insemination. Thus, the use of additives which may improve spermatozoa properties may be comprehend as a tool for intensification of rabbit breeding (Carluccio et al., 2004). Addition of sources of energy or modulators of cell cAMP may enhance the spermatozoa motility (Maréchal et al., 2017; Stephens et al., 2013). Therefore, synergic effect of beneficial bioactive compounds along with antioxidant activity of taurine might result in improved properties of spermatozoa (Tirpák et al., 2016).

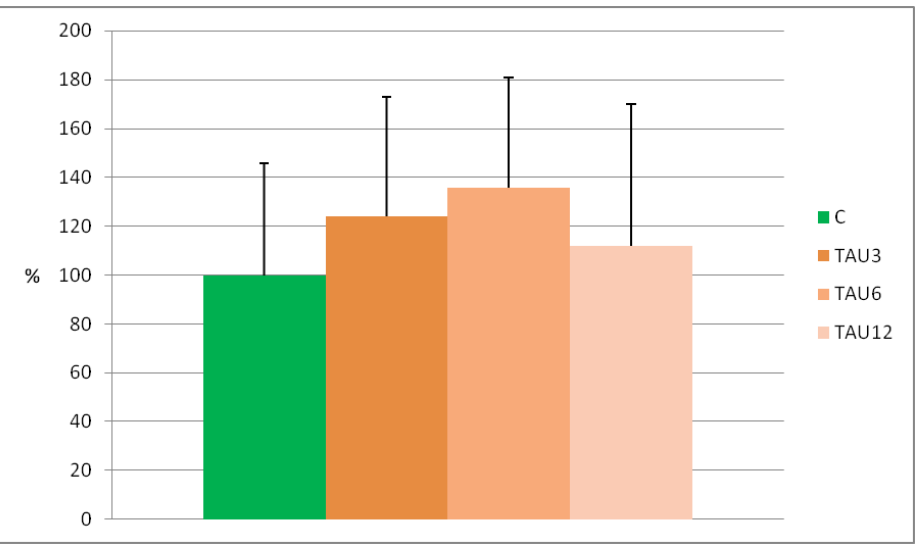

Figure 1 The effect of various doses of taurine on the viability (\%) of rabbit spermatozoa $(n=9)$ assessed after 270 minutes of incubation. Each bar represents mean $( \pm \mathrm{SD})$ optical density as the percentage of controls, which symbolize $100 \%$. The level of significance was set at $* \mathrm{P}<0.05$; $* * \mathrm{P}<0.01$; $* * * \mathrm{P}<0.001$. C 0 ; TAU3 - 3.125; TAU6 - 6.250; TAU $12-12.5 \mathrm{mM}$ of taurine. 


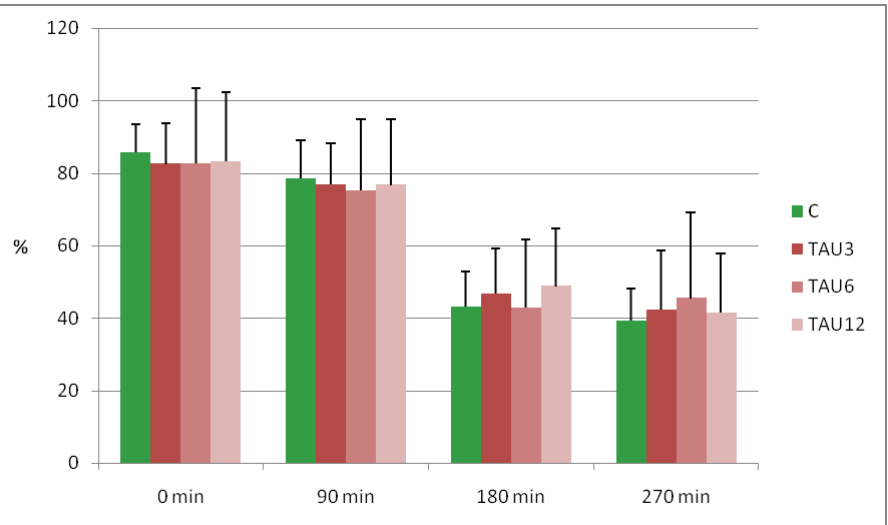

Figure 2 The effect of various doses of taurine on the motility (\%) of rabbi spermatozoa $(\mathrm{n}=9)$ at $0 \mathrm{~min}, 90 \mathrm{~min}, 180 \mathrm{~min}, 270 \mathrm{~min}$. Each bar represents mean $( \pm$ SD) of 7 diverse sub-measurements of 7 different fields. The level of significance was set at $* \mathrm{P}<0.05$; $* * \mathrm{P}<0.01 ; * * * \mathrm{P}<0.001$. C -0 ; TAU3 - 3.125; TAU6 - 6.250; TAU $12-12.5 \mathrm{mM}$ of taurine.

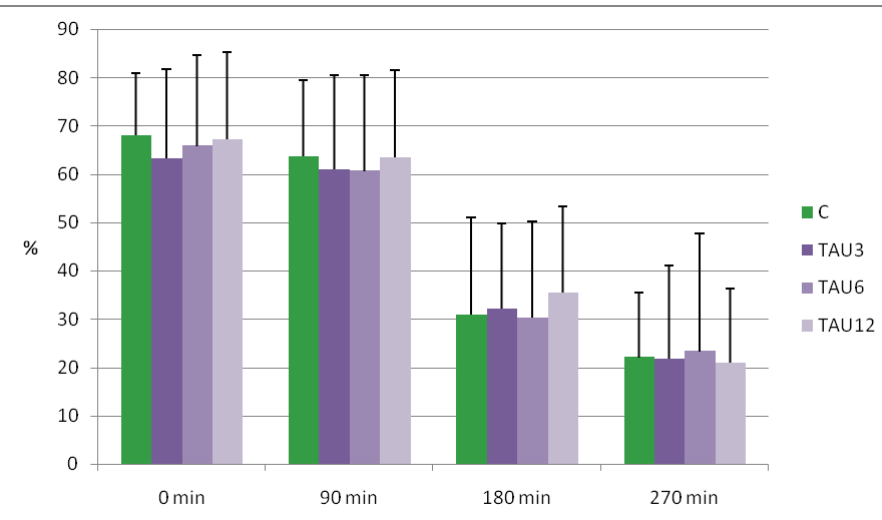

Figure 3 The effect of various doses of taurine on the progressive motility (\%) of rabbit spermatozoa $(\mathrm{n}=9)$ at $0 \mathrm{~min}, 90 \mathrm{~min}, 180 \mathrm{~min}, 270 \mathrm{~min}$. Each bar represents mean $( \pm \mathrm{SD})$ of 7 diverse sub-measurements of 7 different fields. The level of significance was set at $* \mathrm{P}<0.05 ; * * \mathrm{P}<0.01$; $* * * \mathrm{P}<0.001 . \mathrm{C}-0$; TAU3 3.125 ; TAU6 - 6.250; TAU $12-12.5 \mathrm{mM}$ of taurine.

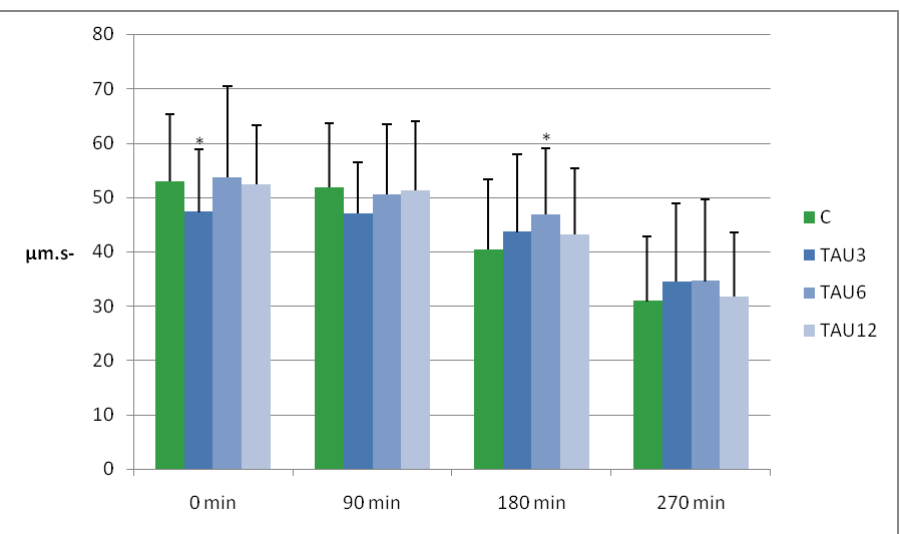

Figure 4 The effect of various doses of taurine on the velocity curved line ( $\mu \mathrm{m} . \mathrm{s}$ $\left.{ }^{1}\right)$ of rabbit spermatozoa $(\mathrm{n}=9)$ at $0 \mathrm{~min}, 90 \mathrm{~min}, 180 \mathrm{~min}, 270 \mathrm{~min}$. Each bar represents mean $( \pm \mathrm{SD})$ of 7 diverse sub-measurements of 7 different fields. The level of significance was set at $* \mathrm{P}<0.05$; $* * \mathrm{P}<0.01$; $* * * \mathrm{P}<0.001$. C -0 ; TAU3 3.125 ; TAU6 - 6.250; TAU $12-12.5 \mathrm{mM}$ of taurine

\section{CONCLUSION}

We conclude that low taurine concentrations have beneficial effect on rabbit spermatozoa from the perspective of long-term incubation. This phenomenon might be used in artificial insemination with cooled semen or in immediate insemination due to higher maintenance of viability, motility and velocity curved line along with the raising time interval at rabbit body temperature. Outcome of our study shows improved viability and motility in in vitro conditions. Nevertheless, improved fertilization rate could not be claimed solely on the base of our study. Since the highest concentration of taurine was not the most effective, we may suggest that the most optimal concentration of taurine in rabbit semen doses is $6.250 \mathrm{mM}$. More extensive research focused on egg fertilization might reveal the effectivity of taurine use.
Acknowledgments: This work was funded by projects VEGA 1/0760/15, VEGA 1/0857/14, APVV-16-0289, APVV-15-0544, KEGA 006/SPU-4/2015 and AgroBioTech Research Centre built in accordance with the project Building „AgroBioTech" Research Centre ITMS 26220220180

\section{REFERENCES}

Asha, K. K., \& Devadasan, K. (2013). Protective effect of taurine on the mitochondria of albino rats induced with fulminant hepatic failure. Biomedicine \& Preventive Nutrition, 3(3), 279-283. https://doi.org/10.1016/j.bionut.2012.12.007

Bucak, M. N., \& Tekin, N. (2007). Protective effect of taurine, glutathione and trehalose on the liquid storage of ram semen. Small Ruminant Research, 73(1-3) 103-108. https://doi.org/10.1016/j.smallrumres.2006.12.001

Bucak, M. N., Tuncer, P. B., Sariözkan, S., Ulutaş, P. A., Çoyan, K., Başpinar, N., \& Özkalp, B. (2009). Effects of hypotaurine, cysteamine and aminoacids solution on post-thaw microscopic and oxidative stress parameters of Angora goat semen. Research in Veterinary Science, 87(3), 468-472. https://doi.org/10.1016/j.rvsc.2009.04.014

Carluccio, A., Robbe, D., De Amicis, I., Contri, A., Tosi, U., Russo, F., \& Paoletti, M. (2004). Artificial Insemination in Rabbits: Laboratory and Field Trial With Three Different Semen Extenders. World Rabbit Science, 12, 65-79. Huxtable, J. (1992). Actions of Taurine. Physiological Reviews, 72(1), 101-163. Chen, Y., Foote, R. H., \& Brockett, C. C. (1993). Effect of sucrose, trehalose, hypotaurine, taurine, and blood serum on survival of frozen bull sperm. Cryobiology. https://doi.org/10.1006/cryo.1993.1042

Chhillar, S., Singh, V. K., Kumar, R., \& Atreja, S. K. (2012). Effects of Taurine or Trehalose supplementation on functional competence of cryopreserved Karan Fries semen. Animal Reproduction Science, 135(1-4), 1-7. https://doi.org/10.1016/j.anireprosci.2012.08.029

Jambor, T., Tvrdá, E., Tušimová, E., Kováčik, A., Bistáková, J., Forgács, Z., \& Lukáč, N. (2017). In vitro effect of 4-nonylphenol on human chorionic gonadotropin (hCG) stimulated hormone secretion, cell viability and reactive oxygen species generation in mice Leydig cells. Environmental Pollution, 222 219-225. https://doi.org/10.1016/j.envpol.2016.12.053

Jang, H., Kim, S., Kim, J., Park, C., Lee, H. \& Yang, B. (2006). Effects of Antioxidants on Sperm Motility During in Vitro Storage of Boar Semen. Kor J Gerontol, Vol, 16 No. 6(11), 47-51.

Kothari, S., Thompson, A., Agarwal, A., \& Plessis, S. S. D. (2010). Free-radicals: Their beneficial and detrimental effects on sperm function. Indian J Exp Biol, 78(May), 1700-8

Lucio, C. F., Regazzi, F. M., Silva, L. C. G., Angrimani, D. S. R., Nichi, M., \& Vannucchi, C. I. (2016). Oxidative stress at different stages of two-step semen cryopreservation procedures in dogs. Theriogenology, 85(9), 1568-1575 https://doi.org/10.1016/j.theriogenology.2016.01.016

Maréchal, L., Guillemette, C., Goupil, S., Blondin, P., Leclerc, P., \& Richard, F. (2017). Cyclic nucleotide phosphodiesterases in human spermatozoa and seminal fluid: Presence of an active PDE10A in human spermatozoa. Biochimica et Biophysica Acta - General Subjects, 1861(2), 147-156. https://doi.org/10.1016/j.bbagen.2016.11.006

Martínez-Páramo, S., Diogo, P., Dinis, M. T., Soares, F., Sarasquete, C., \& Cabrita, E. (2013). Effect of two sulfur-containing amino acids, taurine and hypotaurine in European sea bass (Dicentrarchus labrax) sperm cryopreservation. Cryobiology, 66(3), 333-338. https://doi.org/10.1016/i.cryobiol.2013.04.001

Michael, A., Alexopoulos, C., Pontiki, E., Hadjipavlou-Litina, D., Saratsis, P., \& Boscos, C. (2007). Effect of antioxidant supplementation on semen quality and reactive oxygen species of frozen-thawed canine spermatozoa. Theriogenology, 68(2), 204-212. https://doi.org/10.1016/j.theriogenology.2007.04.053

Ripps, H., \& Shen, W. (2012). Review: taurine: a "very essential" amino acid. Molecular Vision, 18(November), 2673-86.

Sariözkan, S., Bucak, M. N., Tuncer, P. B., Ulutas, P. A., \& Bilgen, A. (2009). The influence of cysteine and taurine on microscopic-oxidative stress parameters and fertilizing ability of bull semen following cryopreservation. Cryobiology, 58(2), 134-138. https://doi.org/10.1016/j.cryobiol.2008.11.006

Slanina, T., Petrovičová, L., Miškeje, M., Kňížat, L., Mirda, J., Lukáč, N., ... Massányi, P. (2015). The effect of diluent, temperature and age on turkey spermatozoa motility in vitro. Journal of Applied Animal Research, 43(2), 131136. https://doi.org/10.1080/09712119.2014.928627

Stephens, T. D., Brooks, R. M., Carrington, J. L., Cheng, L., Carrington, A. C., Porr, C. A., \& Splan, R. K. (2013). Effects of pentoxifylline, caffeine, and taurine on post-thaw motility and longevity of equine frozen semen. Journal of Equine Veterinary Science, 33(8), 615-621. https://doi.org/10.1016/j.jevs.2012.10.004 Tirpák, F., Slanina, T., Hanusová, K., Massányi, P. (2016). Effect of SMM semen extenders on rabbit spermatozoa motility and viability. Proceedings of International PhD Students Conference 829-834.

Tirpák, F., Slanina, T., Ofúkaný, M., Lukáč, N., \& Massányi, P. (2015). Effect of taurine on bovine spermatozoa motility parameters following cryopreservation. Slovak Journal of Animal Science, 48(2), 49-56.

Tvrdá, E., Lukáč, N., Jambor, T., Lukáčová, J., Hashim, F., \& Massányi, P. 
(2016). In vitro supplementation of lycopene to bovine spermatozoa: Effects on motility, viability and superoxide production. Animal Science Papers and

Reports, 34(4), 319-328. https://doi.org/10.15414/jmbfs.2015.4.4.336-341 